\title{
Determinantes da Demanda Brasileira por Importação de Arroz: uma abordagem não linear
}

\author{
Rafael Pentiado Poerschke ${ }^{1}$ e Igor Alexandre Clemente de Morais ${ }^{2}$
}

\begin{abstract}
Resumo: O presente trabalho propõe o uso de modelos de correção de erros para avaliar o comportamento da função de demanda brasileira por arroz em casca e beneficiado entre janeiro de 1995 e junho de 2010. O objetivo geral é testar se os modelos não lineares conseguem representar as relações de curto e longo prazo na demanda. Em geral, os impactos de longo prazo da renda e preço doméstico foram os principais determinantes das importações, com evidências de que o arroz é um bem inferior. O preço de importação contribui menos que proporcionalmente, ao passo que o importador parece ajustar a quantidade importada do período com certo grau de defasagem. A dinâmica de correção do modelo a choques foi atenuada nas estimativas não lineares mensais, enquanto permaneceu praticamente estável nas estimativas trimestrais. Ainda conforme os resultados é possível afirmar que os ciclos de expansão das importações se mostraram fortemente relacionados a eventos climáticos adversos e às alterações da política comercial. Os resultados chamam a atenção para a influência do governo sobre a importação via incentivo tarifário com terceiros - o que se mostra útil para contornar períodos de escassez de oferta do produto no Brasil e no Mercosul.
\end{abstract}

Palavras-chaves: Cointegração, modelo de correção de erros, mudança de regime, equação de demanda.

Abstract: The objective of this study is to analyze the behavior of the Brazilian demand for rough and milled rice between January 1995 and June 2010. The main aim is to test the adequacy of linear and non-linear relations that represent short and long-term variables on the demand. In general, long-term impacts from income and domestic price were the most determinants to imports and the rice can be seen as an inferior good. The price of imports contributes less than proportionately, while the importer seems to adjust the quantity with some lag. The correction of the model to short-term shocks was eased in monthly non-linear estimates, while it remained nearly stable in quarterly estimates. Finally, one can say that import cycles were strongly related to adverse climatic events, as well as to alterations

1. Professor Unifra e Doutorando PPGEEI/UFRGS. E-mail: faecohaiti@yahoo.com.br

2. Professor do Programa de Pós-graduação em Economia/Unisinos E-mail: igoracmorais@gmail.com 
in trade policy. The results draw attention to the influence of the government on the imports through pricing incentives to third parties - what proves to be helpful to overcome supply shortages in Brazil and Mercosur.

Key-words: Cointegration, error correction model, switching regime, demand function.

Classificação JEL: Q11, F10, C24.

\section{Introdução}

O rápido crescimento do comércio mundial, ocorrido especialmente após 2001, não foi homogêneo entre países e produtos. Em alguns casos, mesmo diante de características comuns, como é o caso do arroz, o que poderia facilitar sua comercialização, essa dinâmica de transformações comerciais não foi verificada. Segundo dados da FAO (2011), apenas 5\% da produção mundial arroz foi exportada ao final da década de 2000. Um resultado praticamente estável relativamente aos 3\% da década de 1990. Embora o Brasil ocupe a nona posição entre os maiores produtores mundiais, o saldo comercial é negativo e produz um efeito difuso sobre a cadeia. Dentro da porteira, manifesta-se de forma preocupante e transpóe o comércio internacional como nocivo, ao passo que a indústria não compartilha a mesma opinião [ver Perotti (2000)].

Sob esse prisma, o decurso da história econômica dos últimos 30 anos foi perverso com a cadeia produtiva de arroz no Brasil. Um dos maiores desafios da cadeia, sem dúvida, foi o processo de abertura da economia e seus impactos sobre a balança comercial do cereal. O Brasil, antes exportador líquido do produto, passou a importar pequenas quantidades nos anos 1980, mas, nos 1990, esse movimento se intensificou. Na década seguinte, as importações não recrudesceram por completo, pois alteraram períodos de queda e expansão. Depreende-se que muito do comportamento das importações se deveu, em parte, a problemas climáticos ou mesmo influenciada pelas mudanças das condições macroeconômicas internacionais.

Primeiramente, a conclusão da transição de zona de livre comércio para uma união aduaneira no Mercosul expôs o mercado doméstico à concorrência externa, haja vista a redução das barreiras tarifárias e a eliminação de restrições quantitativas das importações de produtos agrícolas e uma tarifa externa comum (TEC) para o arroz. De outro lado, a formação do Mercosul possibilitou um grande volume de comércio criado na Argentina e Uruguai, ver Nonnenberg e Mendonça (1999). Esse ganho de comércio explica parcialmente os últimos 10 anos das importações, quando o bloco respondeu por $90 \%$ do volume importado de arroz do Brasil. Entretanto, outros fatores tornaram-se também relevantes como variáveis determinantes da demanda por importação: (i) a estabilidade de preços pós-Plano Real e seu impacto direto sobre a renda dos consumidores; (ii) apreciação da taxa de câmbio no período anterior à flexibilização; (iii) eventos climáticos sazonais e (iv) o avanço da produção nacional via elevações de produtividade. Assim, tirar conclusões dos impactos que essas diferentes condições do mercado produzem sobre o comportamento da importação de arroz torna-se uma tarefa complexa. 
Apesar da importância econômica e social que desempenha a atividade orizícola no Brasil, os estudos recentes que se propuseram a verificar os determinantes da demanda por importação de arroz em casca no Brasil restringem-se a Nonnenberg e Mendonça (1999), com dados anuais, e Capitani et al. (2011). Como forma de complementar esses resultados, o presente trabalho tem como objetivo principal identificar as elasticidades envolvidas na demanda por importação de arroz e, além disso, avaliar características cíclicas e modelar as mudanças de regime que envolveram essa dinâmica.

Esse estudo fornece duas importantes contribuições para o tema. Em primeiro lugar, é uma forma de preencher uma lacuna na pesquisa da área no Brasil. Em segundo, fornecer subsídios para que formuladores de políticas públicas, investidores e produtores melhor entendam os efeitos de mudanças no mercado e seus reflexos sobre as importações de arroz. Finalmente, os resultados encontrados sinalizaram uma relação inversa entre renda e importação de arroz e uma significativa relevância para o preço doméstico. Também foi possível identificar a presença de distintos comportamentos entre as importações de arroz em casca e beneficiado.

Esse artigo está organizado em seis seções, além dessa introdução. A segunda faz uma revisão dos aspectos empíricos sobre demanda por importação no Brasil. A terceira seção destaca a metodologia utilizada com o modelo teórico desenvolvido. A quarta seção reúne os resultados da pesquisa e a quinta apresenta a conclusão.

\section{Revisão bibliográfica}

O fundamento teórico da demanda por importação remete à típica curva de demanda discutida na microeconomia. Nesse caso, além do preço do produto que, no presente artigo é o arroz, também devem ser consideradas variáveis relacionadas à renda e o preço do bem substituto. No primeiro caso, como se trata de uma curva de demanda por importações, deve-se ava- liar a evolução da renda interna e que pode ser complementada pela medida de Utilização da Capacidade Instalada, útil para medir os movimentos cíclicos da renda. No segundo caso, a literatura internacional aponta a necessidade de incluir, além do preço do produto no mercado internacional, ver Capitani et al. (2011), outras duas variáveis que podem distorcer seu valor no mercado interno, a taxa de câmbio real e as tarifas de importação.

Diversos artigos apontam as diferenças no tratamento da formulação dos modelos de demanda, ver Goldstein e Khan (1978), Zini (1988) e Portugal (1993). De forma geral, considerando-se que o País é pequeno e, dessa forma, não influencia o preço do bem no mercado internacional, é possível estimar apenas uma equação de demanda.

$\mathrm{Na}$ linha de pesquisa para dados da economia brasileira destacam-se os trabalhos de Dib (1981), Zini (1988), Portugal (1992), Carvalho e Parente (1999), Carvalho e Negri (2000) e Morais e Portugal (2005). Contudo, há poucos estudos relacionados aos produtos do agronegócio. Osaki (2003) analisou os determinantes da oferta e demanda por cebola argentina pelo Brasil, a partir de uma demanda invertida que revelou a relevância do preço de importação na demanda e que o bem em questão era inferior. Santos e Barros (2006) estimaram os efeitos da abertura comercial sobre o setor lácteo brasileiro e concluíram que o preço de importação, renda e taxa de câmbio foram significativos em explicar as importações. Capitani et al. (2011), com um Modelo Autorregressivo Vetorial (VAR), analisaram a relação comercial do arroz no Mercosul. Especificamente, propuseram relações contemporâneas do excesso de demanda doméstica por arroz, do preço de importação do Mercosul, do preço interno, da renda interna brasileira e taxa de câmbio efetiva. Os resultados apontaram para a forte relação do volume importado de arroz com o preço doméstico, além da relativa importância da taxa de câmbio entre 1989 e 2008. A Tabela 1 mostra um resumo dessas diferentes formulações e resultados para as elasticidades. 
Tabela 1. Estudos comparativos de demanda por importação no Brasil

\begin{tabular}{|c|c|c|c|c|c|c|c|c|}
\hline \multirow{3}{*}{ Autores } & \multirow{3}{*}{ Período* } & \multirow{3}{*}{ Forma $^{1}$} & \multirow{3}{*}{ Agregação } & \multicolumn{5}{|c|}{ Elasticidades } \\
\hline & & & & \multicolumn{2}{|c|}{ Longo Prazo } & \multicolumn{2}{|c|}{ Curto Prazo } & \multirow{2}{*}{ Ciclo } \\
\hline & & & & Preço & Renda & Preço & Renda & \\
\hline Braga e Markwald (1983) & A1959-1981 & MQ3E & Agregado & $-0,487$ & 2,525 & - & - & \\
\hline \multirow[t]{2}{*}{ Zini (1988) } & T1970-1989 & MQ2E & Agregado & $-0,480$ & 3,280 & - & - & 3,310 \\
\hline & & & Agrícolas & $-0,430$ & 3,250 & - & - & 1,830 \\
\hline Portugal (1992) & T1976-1988 & $\mathrm{KF}$ & Agregado & $-0,910$ & 0,344 & $-0,476$ & 0,301 & 3,685 \\
\hline Castro e Cavalcanti (1997) & A1955-1995 & MCE & Agregado & - & - & $-0,450$ & 2,080 & - \\
\hline \multirow[t]{2}{*}{ Carvalho e Parente (1999b) } & M1978-1996 & MCE & Intermediários & $-1,406$ & 1,337 & $-0,350$ & 6,146 & - \\
\hline & & & N-Duráveis & $-2,003$ & 7,150 & 0,580 & 9,106 & - \\
\hline Resende (2000) & T1978-1998 & MCE & Agregado & $-1,391$ & 0,543 & $-0,235$ & 0,649 & - \\
\hline Carvalho e Negri (2000) & T1978-1998 & MCE & Agropecuários & $-1,342$ & 1,200 & $-0,688$ & 2,270 & - \\
\hline Osaki (2003) & M1990-2000 & MQ2E & Cebola & $0,697^{* *}$ & $-0,156$ & - & - & - \\
\hline Morais e Portugal (2005) & A1947-2002 & MS-VEC & Agregado & $-0,94$ & 0,692 & $-0,426$ & 1,706 & 0,339 \\
\hline Santos e Barros (2006) & M1991-2003 & MQ2E & Lácteos & $-1,469$ & 3,706 & - & - & - \\
\hline
\end{tabular}

* A, dados anuais; T, dados trimestrais; M, dados mensais. ** Demanda invertida. ${ }^{1}$ As formas podem ser lidas como MQ2E Mínimos Quadrados em dois estágios e MQ3E, em três estágios; KF como Kalman Filter; MCE como Mecanismo de Correção de Erros e MS-VEC como Markov Switching, respectivamente.

Fonte: Elaboração dos autores.

Como se observa, a maioria dos autores trazidos não abordaram especificamente o capítulo da Nomenclatura Comum do Mercosul (NCM) que contém o arroz de forma desagregada, exceto Capitani et al. (2011), que evidenciaram a importância de variáveis dummy para a estabilidade de seu modelo. Este fato fornece subsídio para novas estimações que considerem a instabilidade dos parâmetros do modelo, assim como uma desagregação a fim de verificar se os determinantes assumem diferentes comportamentos para explicar a demanda por arroz em casca e beneficiado.

\section{Metodologia}

Para analisar empiricamente os determinantes das importações de arroz definiu-se um modelo de economia pequena e assumiu-se o produto doméstico e estrangeiro como substitutos imperfeitos. Assim, parte-se de um modelo geral do tipo:

$$
Q_{i t}=\beta_{0} Y_{i t}^{\beta_{1}} P d_{i t}^{\beta_{2}} P m_{i t}^{\beta_{3}} P \operatorname{Ind} d_{i t}^{\beta_{4}} \varepsilon^{u_{t}}
$$

em que $Q_{i}$ é a quantidade importada de arroz; $P d_{i}$ $=$ Preço doméstico do arroz; $\mathrm{Pm}_{i}=$ Preço externo de importação; $i_{i} d_{i}=$ Produção Industrial Física de arroz beneficiado; $Y_{i}=$ variável que representa a renda e os coeficientes $\beta_{j}$ medem as elasticidades de $Q_{i}$ com relação às variáveis, e $i$ pode ser o arroz em casca, beneficiado ou total. Se aplicado o log na equação 1 tem-se:

$\ln q_{i i}=\alpha+\beta_{1} \ln y_{i i}+\beta_{2} \ln p d_{i i}+\beta_{3} \ln p m_{i}+\beta_{4} \ln i n d_{b_{i}}+\varepsilon_{i i}$

em que $\alpha=\ln \beta_{0}, \varepsilon_{i_{t}} \sim \operatorname{NID}\left(0, \sigma^{2}\right)$. Os sinais para as elasticidades das variáveis de acordo com a teoria econômica, podem ser observados no Quadro 1, a seguir.

Apesar de a relação de longo prazo fornecer resultados interessantes para a interpretação das elasticidades, é importante destacar que essa formulação não capta os movimentos no ajuste de curto prazo, nem mesmo lança luz sobre a relação de longo prazo que possa existir entre as variáveis. A literatura revisada acerca da existência de raiz unitária em algumas das variáveis em questão faz com que boa parte das conclusões seja afetada por uma tendência estocástica. Johansen (1988) sugeriu uma formulação que represente a cointegração das variáveis abrindo caminho para o uso de um modelo de Mecanismo de Correção de Erros (MEC) com a incorporação de uma vari- 
Quadro 1. Sinais esperados para os coeficientes da equação 2

\begin{tabular}{|c|l|l|}
\hline Coeficiente & \multicolumn{1}{|c|}{ Sinal } & \multicolumn{1}{|c|}{ Interpretação } \\
\hline$\alpha$ & Positivo & Médias das importações; \\
\hline$\beta_{1}$ & Negativo & $\begin{array}{l}\text { Assumindo-se o arroz como um bem inferior, quanto maior for a renda, menor deve ser o consumo } \\
\text { de arroz. Assim, espera-se que a curva de Engel tenha uma porção negativa a partir de determinados } \\
\text { níveis de renda; }\end{array}$ \\
\hline$\beta_{2}$ & Positivo & Um aumento do preço doméstico implica em elevação das importações do bem substituto; \\
\hline$\beta_{3}$ & Negativo & Quanto menor for o preço externo do arroz, maior o incentivo para importá-lo; \\
\hline$\beta_{4}$ & Indefinido & $\begin{array}{l}\text { O sinal não pode ser generalizado entre os tipos de arroz devido à diferença característica nesses } \\
\text { mercados que estão em pontos diferentes da cadeia produtiva. Quanto maior o nível de produção } \\
\text { interna do arroz em casca e total espera-se que a demanda por importação ou por arroz nacional seja } \\
\text { maior (sinal positivo); Porém, para o arroz beneficiado, espera-se um sinal negativo. }\end{array}$ \\
\hline
\end{tabular}

Fonte: Elaboração dos autores.

ável latente para diferentes regimes a partir de Krolzig (1998). Diante da presença de não linearidade, a equação 2 passaria a ser expressa pela equação 3, preservando as informações de curto e longo prazo em $\varepsilon_{i-1}$.

$$
\Delta q_{i t}=\alpha_{\left(s_{i}\right)}+\beta_{\left(s_{i}\right)}\left(\gamma^{\prime} q_{i-1}\right)+\sum_{i=1}^{n-1} \Gamma_{i\left(s_{i}\right)} \Delta z_{t-1}+\varepsilon_{t}
$$

em que $\Delta$ denota o operador de primeira diferença; $\alpha_{\left(s_{i}\right)}$ representa a constante sujeita aos movimentos da variável de regime não observada e estocástica $s_{t} \in(1, \ldots, k) ; \beta_{\left(s_{t}\right)}$ é o parâmetro de ajuste do modelo de longo prazo e $\Delta z_{t-1}$ é a primeira diferença das variáveis independentes. Assim, $\varepsilon_{\left(s_{1}\right)} \sim \operatorname{NID}\left(0, \Sigma_{\left(s_{1}\right)}\right)$ é o erro aleatório e representa os resíduos gaussianos também governados pela variável de regime, definida pelas probabilidades de transição entre os estados, $P_{i j}=\operatorname{Pr}\left(s_{t+1}=j / s_{t}=i\right) \operatorname{com} \sum_{j=1}^{k} P_{i j}$. Para uma discussão sobre modelos de mudança de regime, ver Hamilton (1989); para aplicações do tipo MS-VEC, ver Krolzig $(1996,1998)$ e, aplicado a séries brasileiras, Morais (2003), Morais e Portugal (2005) e Morais et al. (2010).

Destaca-se que a estimação da equação 3 permite que se possam fazer diferentes investigações sobre o impacto entre as variáveis; porém, há diversas questões específicas relacionadas ao comportamento dos dados que devem ser consideradas, como por exemplo, a não linearidade de séries temporais causada por quebras estruturais, que violam a hipótese de estacionaridade e normalidade. Nesse caso, é muito comum o uso de variáveis dummy para contornar essas questões, sendo que poucos trabalhos aplicam técnicas alternativas, como por exemplo, a mudança de regime markoviano (MS). Este caracteriza as alterações como sendo endógenas e são captadas pelo próprio modelo.

\subsection{Bases de dados}

Para o caso das variáveis dependentes, as séries referentes às importações de arroz pelo Brasil foram coletadas para quantidades (em toneladas) e valores (US\$ FOB) via sistema Alice da Secex/MDIC, correspondendo ao capítulo 10, posição 6 do Sistema Harmonizado de Designação e de Codificação de Mercadorias (SH), na totalidade dos subgrupos 10 (para arroz em casca) e 20 (beneficiado).

Relativo às variáveis independentes, ind refere-se à produção industrial de arroz beneficiado, medida pela pesquisa industrial mensal de produção física (IBGE/PIM-PF). Para o preço doméstico do arroz foram coletadas séries com fontes distintas. As séries de arroz em casca foram obtidas junto à Secretaria da Agricultura e do Abastecimento do Estado do Paraná, Departamento de Economia Rural (Seab-PR) e no Instituto Riograndense do Arroz (IRGA), ambas referentes à saca de $50 \mathrm{~kg}$ do preço pago ao produtor. A série referente ao preço médio pago pelo quilo $(\mathrm{kg})$ ao produtor foi obtida na Fundação Getúlio Vargas (FGV). Para o arroz beneficiado, as opções de séries tiveram as mes- 
mas fontes; porém, os preços eram referentes ao preço médio pago pelo fardo de $30 \mathrm{~kg}$ de arroz beneficiado no atacado. Os valores expressos em reais foram deflacionados pelo Índice Nacional de Preços ao Consumidor Amplo (IPCA), referente a agosto de 2010.

A série do câmbio é o índice da taxa de câmbio efetiva real para o setor da agropecuária, mensurada pelo Instituto de Pesquisa Econômica Aplicada (IPEA). Para a variável renda, três séries foram selecionadas. Uma refere-se ao Produto Interno Bruto medido a preços de mercado pelo índice encadeado, coletada no Banco Central do Brasil (BCB). As duas outras se referem ao salário real da indústria, bem como a média salarial na indústria paulista, obtida na Federação das Indústrias de São Paulo (FIESP).

Para a variável que representa o preço de importação, foram selecionadas cinco diferentes séries - todas foram convertidas para moeda doméstica pela taxa de câmbio efetiva real da agropecuária. Uma dessas foi estimada por meio dos dados de importação via Alice Secex/MDIC, conforme especificado por Leamer e Stern (1970), que sugere o conceito de valor médio de importação (quociente entre a quantidade e o valor do bem importado). Também foram usadas séries referentes ao preço da tonelada de arroz em casca na Argentina, na Tailândia, o preço-convênio da saca do arroz no Uruguai e o preço pago ao produtor americano.

Todas as séries são mensais com início em janeiro de 1995 a junho de 2010, exceto o preço do arroz beneficiado fornecido pelo IRGA, que data de janeiro de 1997 a junho de 2010. Tratamentos adicionais foram feitos aos dados, como a construção de número índice com todas na mesma base (média $2002=100$ ), bem como aplicado o logaritmo.

\section{Resultados}

Esta seção é dividida em três partes. Em um primeiro momento, apresentam-se as variáveis envolvidas e suas características. Posteriormente, abordam-se os resultados para os modelos lineares de curto e longo prazo. Optou-se também por estimativas com dados mensais e trimestrais e foi feita a investigação de aspectos da sazonalidade e presença de outliers.

\subsection{Características dos dados}

A demanda por importação de arroz foi avaliada a partir da quantidade classificada como casca e também para o arroz beneficiado. Tal como os estudos característicos de demanda, usou-se a renda, preço doméstico, preço externo e a capacidade instalada como variáveis independentes [ver Braga e Markwald (1983), Zini (1988), Portugal (1992), Carvalho e Negri (2000), Morais e Portugal (2005) e Santos e Barros (2006) para aplicações a outros bens].

Algumas das variáveis envolvidas são comuns entre os modelos estimados, como por exemplo, a produção industrial de arroz, a renda e os preços internacionais. Verificou-se que os preços internacionais apresentam pelo menos duas fases distintas. Um primeiro momento, marcado por preços declinantes até o final de 2001 e interrompido por uma longa tendência altista. Essa foi revertida somente no segundo trimestre de 2008 por conta dos efeitos da crise financeira internacional. Tal reversão do comportamento dos preços se deu concomitante ao início da crise subprime e não se limitou apenas ao arroz, tendo se estendido a outras commodities agrícolas. Não há clareza na literatura sobre as causas da elevação dos preços entre 2002 e 2008, mas depreende-se que a alta do preço dos produtos agrícolas assenta-se em fatores que, em grande parte, foram globais e de natureza macroeconômica [para mais detalhes acerca desses aspectos ver Good e Irwin (2008), Irwin et al. (2009) e Frankel e Rose (2009)].

Os preços de importação do cereal praticados pelo Brasil parecem ter seguido de perto a tendência internacional, conforme mostra a Figura 1. Para a quantidade de arroz em casca se percebe uma tendência de queda no volume importado entre 1998 e 2003 acompanhado do aumento dos preços. 
Figura 1. Índice trimestral do preço de importação e doméstico do arroz (1995:01 - 2010:02)
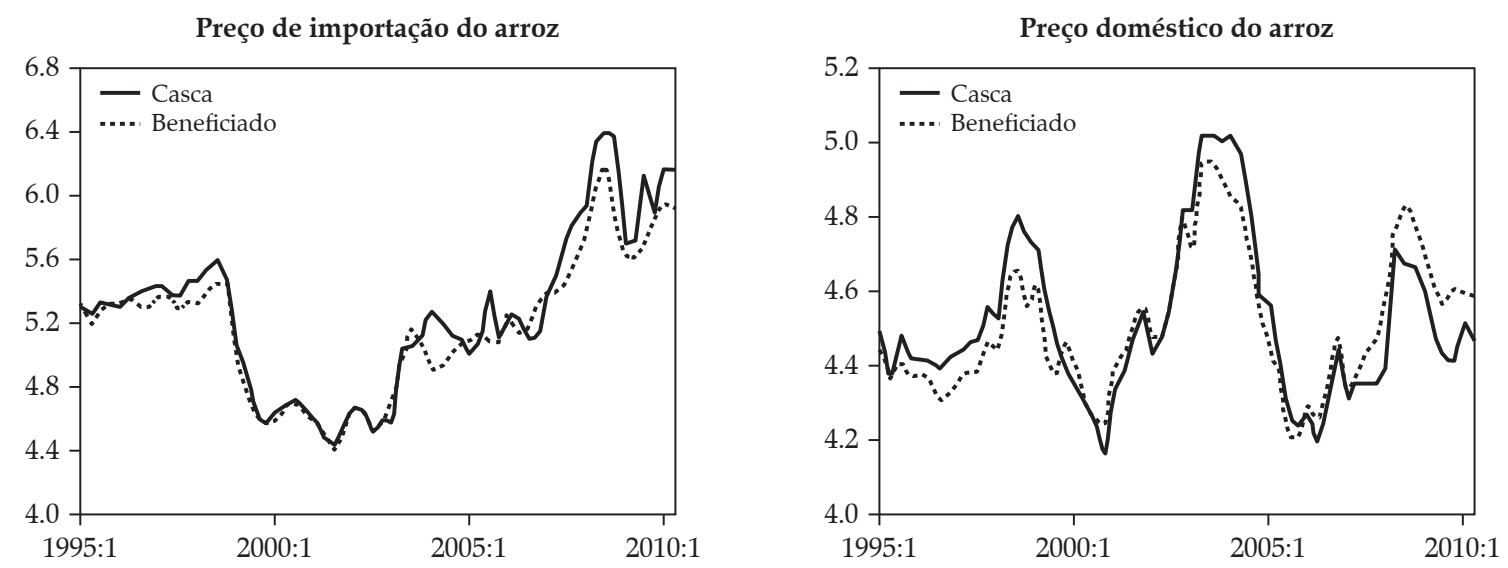

Fonte: MDIC, IRGA e Conab.

Para a cadeia produtiva nacional, o período abrange importantes acontecimentos, como o aumento da concentração da indústria de beneficiamento gaúcha e a expansão do processamento na direção dos grandes centros consumidores brasileiros. Compreende ainda uma fase de preços históricos em alta até o terceiro trimestre de 2008. Além disso, a queda do volume importado pode estar atrelada à aceleração da produção na década de 2000 e à diversificação das exportações uruguaias, fatores que em parte ajudam a explicar esse fenômeno.

De outro lado, as importações brasileiras de arroz beneficiado oscilaram bastante, ver Figura 2. A expansão recente aconteceu concomitante à internacionalização de algumas indústrias brasileiras do setor de alimentos, mais especificamente pela aquisição de engenhos na América do Sul ${ }^{3}$. Fica evidente também que os preços de importação do arroz beneficiado seguiram a mesma tendência de alta verifica no arroz em casca.

Vale ressaltar a relação das importações brasileiras de arroz com as idiossincrasias da condução das políticas na economia brasileira e internacio-

3. As empresas beneficiadoras do Uruguai e Chile, S. A. Molinos Arroceros Nacionales (Saman) e Tucapel do Chile, respectivamente, foram incorporadas seguindo sua estratégia de internacionalização da indústria brasileira. nal, bem como com problemas climáticos (excesso ou stress hídrico). Conforme proposto por Bry e Boschan (1971), a cronologia ${ }^{4}$ das importações de arroz beneficiado e em casca, Figura 2 e Tabela 2, ressalta quatro e cinco ciclos expansivos, respectivamente. A literatura ${ }^{5}$ aponta uma série de fatores que podem explicar a magnitude desse e dos demais ciclos de importações de arroz que coincidem com fenômenos ligados a mudanças das condições do cenário fundamental desse mercado e, também, a alterações conjunturais das economias brasileira e mundial.

O primeiro deles é praticamente comum para ambos os tipos de arroz, além de mais longo, com duração de 36 meses. O período que compreende o ciclo 1 é concomitante a três importantes eventos sob a ótica da cadeia orizícola brasileira: (i) o período abarca o implementação da União Aduaneira do Mercosul; (ii) tal vantagem tarifária do arroz do Mercosul acontece junto a um Real valorizado, influenciando a formação do preço interno brasileiro e a concorrência intrabloco; e, por fim, (iii) esse período compreende uma das maiores estiagens da região Sul, que resultou em

4. Para maior detalhamento e emprego específico da rotina BB, ver Bry e Boschan (1971).

5. Para revisão histórica e fatos estilizados sobre o arroz, ver Perotti (2000), IRGA (2011), entre outros. 
Determinantes da Demanda Brasileira por Importação de Arroz: uma abordagem não linear

Tabela 2. Estimativas dos ciclos mensais de expansão na importação brasileira de arroz

\begin{tabular}{|c|c|c|c|c|c|c|c|}
\hline \multirow{2}{*}{ Ciclos } & \multicolumn{3}{|c|}{ Arroz em casca } & \multirow{2}{*}{ Ciclos } & \multicolumn{3}{|c|}{ Arroz Beneficiado } \\
\hline & Vale & Pico & Duração & & Vale & Pico & Duração \\
\hline Ciclo 1 & 1995:dez & 1998:dez & 36 meses & Ciclo 1 & 1995:set & 1998:set & 36 mese \\
\hline Ciclo 2 & 2001:mai & 2001:nov & 6 meses & Ciclo 2 & 2001:mai & 2001:out & 5 meses \\
\hline Ciclo 3 & 2002:out & 2003:set & 11 meses & Ciclo 3 & 2002:ago & 2004:fev & 18 mese \\
\hline Ciclo 4 & 2006:fev & 2008:fev & 24 meses & Ciclo 4 & 2005:mai & 2007:jun & 25 mese \\
\hline Ciclo 5 & 2009:jan & 2009:out & 9 meses & & 2008:nov & & \\
\hline Média & & & 17,2 meses & Média & & & 21 meses \\
\hline
\end{tabular}

Fonte: Elaboração própria, baseado nos resultados do emprego da rotina BB.

Figura 2. Índice mensal da quantidade importada (1995:01-2010:06)
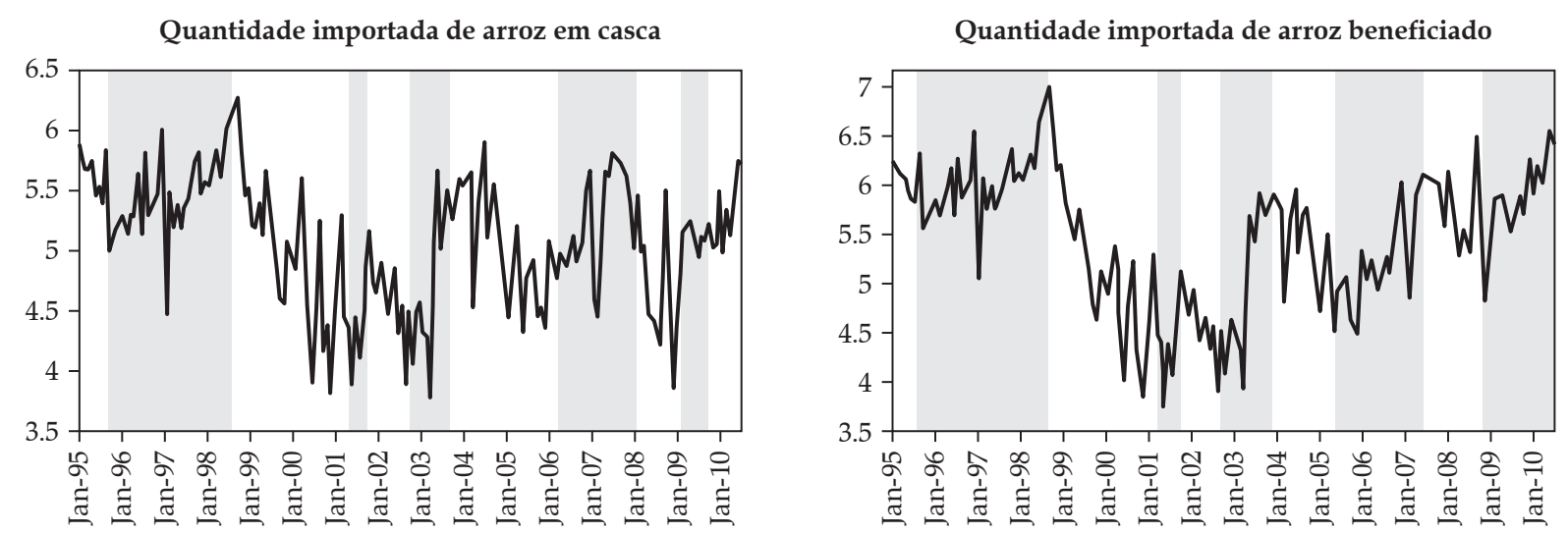

Fonte: MDIC (2011).

queda de $11 \%$ da produção nacional. Esse ciclo, em ambos os casos, se encerra próximo à desvalorização cambial vivenciada em 1999.

Os ciclos do arroz em casca apresentam magnitudes equilibradas entre si, porém, exibem uma média (17,2 meses) inferior à extensão dos ciclos verificados para o arroz beneficiado. Um importante motivo para ajudar a explicar o curto segundo ciclo de expansão assenta-se na estiagem que causou quebras na safra 2000/01.

O terceiro ciclo iniciou-se em outubro de 2002 e estendeu-se até setembro de 2003, perfazendo 11 meses. Dois fatores são importantes para ajudar a explicar esse período: (i) esse intervalo engloba problemas referentes à estiagem da safra 2002/03 e decorrentes do fenômeno El niño; (ii) é concomitante a um período de preços internacionais baixos. A Figura 2 mostra a evolução da importação de arroz e esses respectivos momen- tos expansivos, caracterizados pelas barras de cor cinza.

No quarto ciclo, a distância entre o vale e o pico é relativamente longa, 24 meses, com início em 2006: fev e indo até 2008: fev. Nota-se que o começo do ciclo contempla a estiagem que afetou a safra 2005/06 e seu final coincide com o início da colheita brasileira da safra 2007/08. Por fim, o quinto ciclo, com duração de nove meses apenas, pode estar associado ao período em que o Brasil retomou as exportações de arroz quebrado e beneficiado para o exterior, especificamente no comércio com países da África e Oriente Médio.

No caso do arroz beneficiado, o segundo ciclo (2001: mai a 2001: out) é o mais curto e pode estar ligado à retração da produção nacional (-9\%) da safra 2000/01 em função de adversidades climáticas. O terceiro ciclo, que vai de agosto de 2002 a fevereiro de 2004, com duração média de 18 
meses, coincide igualmente com problemas referentes a uma estiagem ${ }^{6}$ de escala internacional na safra 2002/03 decorrente do fenômeno El niño (que restringiram a oferta de produto verde no Brasil, China e Índia). A fim de garantir o suprimento interno, a Câmara de Comércio Exterior (Camex) isentou de tarifas o arroz beneficiado entre junho de 2001 e dezembro de 2002 [resoluções n. 16, n. 27, n. 42 de 2001 e n. 34 de 2002], ao passo que entre outubro e dezembro de 2003, a tarifa para o arroz foi mantida reduzida pela Camex na casa de 4\% [resolução n. 25 de 2003]. Vale ressaltar que esse período foi marcado por preços internacionais declinantes. $\mathrm{O}$ incentivo às importações via redução de preços externos pode ter sido em parte, atenuado pela desvalorização do Real ao longo do período.

O quarto e último ciclo é relativamente longo, com 25 meses, e compreende alterações tributárias no Brasil ${ }^{7}$ importantes para a cadeia do arroz, bem como uma tendência de valorização do Real e de aquisições de empresas de processamento de arroz na América do Sul por indústrias brasileiras. Ainda, o período engloba duas estiagens que afetaram as safras 2004/05 e 2005/06, ao passo que é um período de preços internos elevados. Finalmente, o pico (junho de 2007) e a posterior fase de retração das importações são coincidentes com um período de queda do comércio internacional em função da crise do subprime e forte elevação dos preços do cereal no mercado interno e externo. Em novembro de 2008, há um vale que corresponde ao período marcado pela exaustão da alta dos preços das commodities, acompanhado de um excesso de chuvas na região Sul (que prejudicou a safra 2009/10) concomitante à retomada da valorização do Real frente ao dólar.

6. A safra 2003/04 foi também afetada pela falta de chuva; contudo, os reflexos para a produção foram pequenos.

7. Alteração/mudanças nas regras do PIS/Cofins foram estabelecidas na Lei Federal n. 10.925/04, publicada em 26 de julho de 2004, cujas mudanças na forma de incidência e no percentual das alíquotas ofereceram vantagem ao produto do Mercosul, aumentando a competitividade do produto beneficiado argentino e uruguaio e também o volume de importações. A alíquota, que era de $9,25 \%$, foi reduzida a zero.
Quanto aos preços domésticos, é possível identificar mudanças de comportamento (na média) nas séries (Figura 1). As séries de arroz beneficiado e casca exibem comportamento semelhante aos preços internacionais, bem como entre si. Contudo, diferente dos preços internacionais, o pico dos preços reais da saca de arroz em casca e do fardo de arroz beneficiado é anterior e compreende o período que vai do último trimestre de 2003 ao primeiro trimestre de 2004.

Por fim, as variáveis em questão parecem exibir algumas características. Por exemplo, no caso da tendência verificada na renda, a literatura salienta que esse resultado pode viesar as estimativas. Ainda, em segundo lugar, é possível que se tenham quebras estruturais que podem ter ocorrido tanto no nível quanto na tendência das séries. Assim, na investigação sobre a estacionaridade das variáveis do modelo, diversos testes de raiz unitária foram feitos para os dados mensais e trimestrais, como Augmented Dickey-Fuller (ADF) e NG-Perron [ver Ng e Perron (2001)]. A fim de evitar resultados espúrios no teste de raiz unitária também foi utilizada a proposta de Perron (1997), que considera a hipótese nula de raiz unitária e quebra estrutural na série determinada endogenamente [para detalhamento, ver Perron (1989, 1997)]. De forma geral, as séries utilizadas nas equações sinalizaram para a não estacionaridade em nível, mas estacionárias quando em primeira diferença.

\subsection{Modelos mensais}

Nesta subseção, as estimativas de modelos lineares ${ }^{8}$ foram feitas com dados mensais ${ }^{9}$ seguindo a equação 2. Embora a discussão referente ao longo prazo $^{10}$ revele padrões importan-

8. O suplemento estatístico e os dados da pesquisa podem ser obtidos com os autores.

9. Diversas equações de longo prazo foram estimadas utilizando o logaritmo do índice dos dados dessazonalizados pelo método X-12. Os critérios para a seleção dos modelos podem ser encontrados na Tabela $1 \mathrm{~A}$ em anexo.

10. O modelo é representado por $q_{c_{t}}=-8,340+0,469 i n d_{b_{t}}+$ $\underset{(0664)}{190 y 1_{t}}+\underset{(0,664)}{1,169 p d c_{c_{i}}}-0, \underset{(0,117)}{483 p m m} 4_{c_{i}}-0 \underset{(0,133)}{0,599 D_{2001: 02}}+\underset{(0,058)}{0,607 q_{c_{-1}-1}}+\varepsilon_{t}$ 
tes, o artigo presa pela discussão dos resultados apontados pelo Mecanismo de Correção de Erros, que capta tanto as informações de curto quanto de longo prazo. Nesse caso, é feita uma comparação entre os resultados do MCE linear e com mudança de regime.

Como primeiro passo é importante investigar a existência, ou não, de raiz unitária, aqui sinalizando que as mesmas são I(1) em nível. A seguir, é aplicado o teste de cointegração de Johansen(1988), confirmando a existência de um vetor de cointegração ${ }^{11}$ e o teste de Gregory e Hansen (1996) para identificar a presença de quebra estrutural no vetor de cointegração. Esse sinaliza para a construção de um modelo mais completo, que preserve as relações de curto e longo prazo.

A equação 4 representa o melhor ajuste de curto prazo para as importações de arroz em casca. O parâmetro que sinaliza a velocidade de correção dos desequilíbrios no longo prazo, dada por $\varepsilon_{c_{1-1}}$, exibe um ajuste relativamente lento, ou seja, 18\% dos desequilíbrios são compensados a cada mês. Segundo Carvalho e Parente (1999), para bens não duráveis o ajuste seria mais significativo, de $28 \%$. Todos os parâmetros foram estatisticamente significativos, exceto aquele ligado à renda ${ }^{12}$. Ressalta-se que o ajuste das importações a variações positivas no preço internacional no mês anterior não são compensados no período. O sinal do parâmetro relacionado à criação do Mercosul mostra os sinais do arrefecimento da importação, bem como o reflexo do aumento da produção doméstica de arroz quando destinado para beneficiamento.

$$
\begin{aligned}
& \Delta q_{c_{t}}=\underset{(0,066)}{0,111}-\underset{(0,031)}{0,178} \varepsilon_{c_{t-1}}-0, \underset{(0,060)}{412 \Delta q_{c_{t-1}}-1, \underset{(1,706)}{965 \Delta y} 1_{t-6}+} \\
& +3, \underset{(0,750)}{451 \Delta p m} 4_{c_{t-1}}-2, \underset{(0,662)}{154 \Delta p d 2_{c_{t-3}}-0, \underset{(0,086)}{219 D}}
\end{aligned}
$$

11. Esse é dado por $\theta=[1 ; 12,194 ; 64,431 ; 28,612 ; 4,279 ;-2,297$; $-187,018 c ;-0,042 t$. Os vetores de cointegração daqui para frente seguem a mesma ordem, ou seja, $\beta=\left[q_{i}\right.$ i ind; renda; pd; pm; constante; tendência].

12. Optou-se por preservar o parâmetro na medida em que a melhor aderência do modelo foi obtida com essa formulação, junto da adição de uma dummy $(D)$ que representa o período de constituição do MERCOSUL.
O teste LR aplicado para arroz em casca indica que o modelo testado apontou características não lineares, $\chi_{(4)}^{2}=48,305$. Conforme Krolzig (1996, 1998), o primeiro passo para a determinação do modelo não linear é especificar o número de regimes que governa os dados. Porém, a variável de estado é desconhecida, o que dificulta determinar, a priori, o número de regimes. Nesse sentido, foram estimados diversos modelos da forma MS(k)-VEC(1), em que $k=2,3$ é o número de regimes e supondo mudança de regime na média, no intercepto, no componente autorregressivo e também na variância. Os critérios de comparação, como Akaike, Hanna-Quinn e Schwarz, foram usados para comparar os resultados entre os modelos.

A melhor formulação é a mostrada na equação 5, com mudança na média e variância e três regimes, que podem ser classificadas em: regime 1 (queda na importação de arroz), regime 2 (estabilidade) e regime 3 (expansão na importação de arroz). Para o modelo não linear MSMH(3)VEC(1), os resultados contrastam, pelo menos em parte, quando comparados ao modelo linear, equação 4. Conforme pode ser visto, todos os parâmetros foram significativos a $1 \%$, exceto a média relativa ao regime 1 , caracterizado pela "retração" da demanda.

$$
\begin{aligned}
& \Delta q_{c_{t}}=-\underset{(0,139)}{0,179} \mu_{1}-\underset{(0,040)}{2} \underset{(0,044)}{235} \mu_{2}-\underset{(0,022)}{0,330} \mu_{3}-0
\end{aligned}
$$

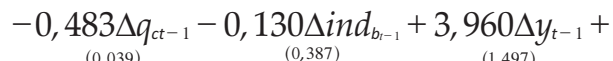

$$
\begin{aligned}
& +1, \underset{(0,583)}{800 \Delta p m} 4_{c_{t-1}}+1, \underset{(0,386)}{710 \Delta p d 2_{c_{t-1}}}
\end{aligned}
$$

O ajuste de curto prazo para o arroz em casca recuou da compensação de $18 \%$ dos desequilíbrios a cada mês no modelo linear para 13\% na equação 5. Ressalta-se o ajustamento da demanda frente a flutuações dos preços no mercado doméstico. Nesse caso, o sinal da elasticidade-preço da demanda sugere que os desequilíbrios do mês anterior são compensados no período. Já o sinal positivo da elasticidade-preço de importação, embora atenuado, vai ao encontro do modelo linear ao ressaltar a defasagem da correção a variações positivas do preço no período anterior. 
Relativo à atividade da indústria, destaca-se que a elevação do beneficiamento não tem impactos significativos na importação de matéria-prima. A renda, por sua vez, mostra maior influência sobre as importações com um período de defasagem.

As estimativas das probabilidades de transição da matriz em 6, sinalizam as possíveis mudanças que podem ocorrer entre os regimes. Assim, a probabilidade de se estar em um regime de queda das importações de arroz em casca (regime 1 ) e nele permanecer, dado por $p_{11}=0,38$, é menor do que a probabilidade de se estar em um regime de estabilidade da demanda e nele permanecer, $p_{22}=0,52$. É importante ressaltar que a probabilidade de se estar e continuar em um estado de expansão de demanda é menor ( $p_{33}$ $=0,31)$ e tende ao equilíbrio $\left(p_{32}=0,68\right)$. No caso do regime 3 , a taxa média de expansão da importação de arroz em casca atinge $0,33 \%$ ao mês.

Por fim, a duração média dos regimes de queda da demanda (1,63 mês) por arroz em casca é superior às expansões (1,46 mês), ao passo que períodos de estabilidade são mais longos, 2,10 meses. O período mais longo das expansões (regime 3) não ultrapassou três meses consecutivos, ao passo que a estabilidade da demanda (regime 2) chegou a oito meses consecutivos.

$$
P_{c}=\left[\begin{array}{lll}
0,386 & 0,266 & 0,004 \\
0,000 & 0,524 & 0,683 \\
0,614 & 0,210 & 0,313
\end{array}\right]
$$

Já os resultados para o arroz beneficiado são relativamente distintos dos alcançados no arroz em casca, a começar pelo modelo mensal de longo prazo de arroz beneficiado. A elasticidade relativa à renda, produção industrial e o intercepto não mostram significância estatística apesar de os sinais estarem de acordo com a teoria. O coeficiente relacionado ao preço doméstico sinalizou que as importações são mais sensíveis a variações internas de preço no arroz beneficiado do que variações do preço internacional.
O teste de Johansen evidencia a existência de pelo menos um vetor de cointegração ${ }^{13}$, sinalizando para a maior sensibilidade dos volumes importados de arroz beneficiado em relação a variações do quantum produzido e à renda. $\mathrm{O}$ resultado para o teste de Gregory e Hansen (1996) não foi como o esperado para esse modelo, pois não foi possível rejeitar a hipótese nula de ausência de cointegração. De qualquer forma, os resultados para MCE na equação 7 mostram um ajuste de curto prazo relativamente maior que o encontrado para o arroz em casca, cerca de $30 \%$ dos desequilíbrios são compensados a cada mês. Ressalta-se, nesse caso, também o ajustamento da demanda frente a flutuações dos preços internacionais e que segue o mesmo padrão identificado para a demanda por arroz em casca, em que variações positivas no mês anterior não são compensadas no período seguinte.

$$
\begin{aligned}
& \Delta q_{b_{t}}=\underset{(0,063)}{0,157}-0, \underset{(0,058)}{306 \varepsilon_{c^{-1}}}-0, \underset{(0,068)}{213 \Delta} q_{b_{t-3}}+\underset{(0,377)}{0,759 \Delta \text { ind }_{c^{-1}-1}}+ \\
& +2, \underset{(1,238)}{867 \Delta r} 1_{t-12}+1 \underset{(0,541)}{518 \Delta p m} 4_{c_{r-1}}-1, \underset{(0,830)}{1,669 \Delta p d 2_{b_{r-2}}}-\underset{(0,077)}{0,228 D}
\end{aligned}
$$

O teste LR revelou a não linearidade do sistema $\chi_{(4)}^{2}=24,691$, assim, a comparação entre diferentes modelos com mudança de regime permite selecionar $k=3$ em $\operatorname{MSIH}(3)-\operatorname{VEC}(1)^{14}$, com mudança de regime no intercepto e variância. De acordo com os resultados da equação 8, o ajuste de curto prazo é inferior ao modelo linear, em que $16 \%$ dos desequilíbrios foram compensados a cada mês. As variáveis relativas aos estados apresentaram-se significativas, ao passo que a produção da indústria, renda e preço doméstico não o foram. Como no caso do arroz em casca, ajustes a variações positivas nos preços internacionais no mês anterior são mais lentamente compensados no período - resultado que também foi encon-

\footnotetext{
13. Esse é dado por $\theta=[1 ;-4,341 ; 3,697 ; 0,556 ; 0,669 ; 1,963 c]$. 14. O modelo linear de longo prazo foi definido por $q_{b_{t}}=0,920-$ $-0, \underset{(0,346)}{115 i n d_{b_{t}}}-0, \underset{(0,511)}{247 y 1_{t}}+\underset{(0,166)}{0,443 p d 2_{b_{t}}}+\underset{(0,079)}{\operatorname{27}} \underset{(0,071)}{270 p m} 4_{c_{t}}-\underset{(2,800: 01 t}{240 D_{20}}+$ $+0,486 q_{b_{t-1}}+\varepsilon_{t}$ $(0,078)$
} 
trado para o modelo linear. O sinal do parâmetro relacionado ao preço doméstico significa que elevações dos preços estimularão as importações no período seguinte.

$$
\begin{aligned}
& \Delta q_{b_{t}}=-\underset{(0,225)}{0,412 v_{1}}+\underset{(0,048)}{4,084 v_{2}}+\underset{(0,132)}{0,513 v_{3}}-0, \underset{(0,070)}{162 \varepsilon_{b_{t-1}}}- \\
& -\underset{(0,150)}{0,378 \Delta q_{b_{t-1}}}-\underset{(0,302)}{0,060 \Delta i n d_{b_{t-1}}}+\underset{(1,255)}{0,461 \Delta y_{t-1}}+ \\
& +0 \underset{(0,435)}{720 \Delta p m} 4_{c_{t-1}}+\underset{(0,712)}{1,034 \Delta p d 2_{b_{t-1}}}
\end{aligned}
$$

As probabilidades de transição mostradas em 9, sinalizam que estar em um regime de queda na demanda e nele permanecer, com $p_{11}=0,47$, foi inferior à probabilidade de se estar em um regime de estabilidade (regime 2) da demanda e nele permanecer, $p_{22}=0,82$. Contudo, para estados de expansão mais significativa da demanda, a probabilidade recua para $p_{33}=0,27$.

$$
P_{b}=\left[\begin{array}{lll}
0,475 & 0,109 & 0,585 \\
0,334 & 0,824 & 0,140 \\
0,191 & 0,067 & 0,275
\end{array}\right]
$$

De fato, os períodos de estabilidade da demanda são mais longos (5,68 meses) que períodos de contração (1,91 mês). O período mais longo de expansões (regime 3) não ultrapassa dois meses consecutivos, ao passo que as quedas na demanda (regime 1) chegaram a seis meses consecutivos, com destaque para os meses de fevereiro a julho de 2008. Além disso, períodos de estabilidade (regime 2) são mais frequentes, além de mais longos. Nesse caso, entre junho de 2005 e dezembro de 2006, foram registrados 18 meses consecutivos de estabilidade. Chama-se a atenção para o período onde vigoraram as resoluções $n$. 16, 17 e 42 de 2001 e n. 34 de 2002 [ver Camex $(2001,2002)]$ que reduziram as tarifas mediante o risco de desabastecimento. Durante os 10 primeiros meses observa-se intensificação das importações (passagem do regime 2, entre junho e agosto de 2001, para o regime 3), enquanto na vigência da resolução n. 25 de 2003 predomina a ocorrência do regime 2.

Os modelos mensais de longo prazo salientaram maior importância de variáveis como a renda e preço doméstico para o arroz em casca, ao passo que para o arroz beneficiado os coeficientes dos parâmetros associados às variáveis foram inferiores à unidade. Já o MCE forneceu informações importantes, pois ajustes da quantidade importada de arroz, em casca e beneficiado, ressaltaram a falta de percepção dos agentes frente a aumento de preços internacionais, principalmente no mercado de arroz em casca.

A melhor adequação do modelo mensal de arroz em casca com mudança de regime na média já era esperado, na medida em que o teste de Gregory e Hansen (1996) ressaltou a existência de um vetor de cointegração mesmo diante de quebra estrutural. Esse comportamento ficou mais claro com a opção do modelo de mudança de regime com três estados para o arroz em casca e beneficiado. A aplicação do MS revela, também, que, embora os regimes de expansão das importações sejam significativos, sua duração é mais curta quando comparado a períodos de queda.

\subsection{Modelos Trimestrais}

Como forma de evitar excessivas oscilações causadas pela periodicidade mensal dos dados, essa subseção faz a mesma abordagem agora com dados trimestrais. Nas estimativas de longo prazo $^{15}$ também dão lugar para os modelos em primeira diferença. Como no modelo mensal para o arroz em casca, o resultado do teste de Gregory e Hansen (1996) rejeitou a hipótese nula para ausência de vetor de cointegração com quebra estrutural. Nesse caso, há evidência de pelo menos um vetor de cointegração e que pode ser definido por $\theta=[1 ; 1,565 ; 9,499 ; 4,470 ;-2,729$; $55,301 c]$. Ressalta-se, nesse vetor, a importância de variáveis como a renda e o preço doméstico na demanda por importação de arroz em casca.

A equação 10 mostra as estimativas para o MCE que melhor se adaptaram aos dados. $\mathrm{O}$ ajuste de curto prazo com dados trimestrais

\footnotetext{
15. O modelo linear de longo prazo foi definido por $q_{c}=\underset{(13,721)}{35,901-}$

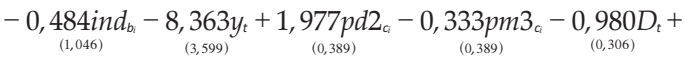
$+\underset{(0,028)}{0,075 t_{t}}+\underset{(0,084)}{0,352 c_{t-1}}+\varepsilon_{t}$
} 
ocorre em $62 \%$ ao trimestre, em torno de $20 \%$ ao mês, em linha com os resultados mensais. Além disso, o ajuste é maior quando comparado aos resultados de Portugal (1992) e Morais e Portugal (2005), bem como aos produtos agropecuários $(-0,5)$ estimados em Carvalho e Negri (2000). Ressalta-se, nesse modelo, um ajustamento defasado da demanda frente a variações dos preços internos no período anterior.

$$
\begin{aligned}
& \Delta q_{c_{t}}=\underset{(0,106)}{0,515}-\underset{(0,098)}{0,616 \varepsilon_{c_{t-1}}}-1, \underset{(0,877)}{\operatorname{0in}} \mathrm{b}_{b_{t-1}}- \\
& -11, \underset{(3,794)}{898 \Delta} y_{t-2}+\underset{(0,499)}{0,758} \underset{p}{7} m 3_{c_{t-1}}-1, \underset{(0,512)}{257 \Delta p d 2_{c_{t-1}}+} \\
& +\underset{(0,528)}{1,954 \Delta p d 2_{c_{t-2}}}-\underset{(0,155)}{0,734 D}
\end{aligned}
$$

De modo geral, com dados trimestrais, as especificações não diferiram substancialmente daquelas encontradas nas estimativas mensais. Os resultados para a demanda por importação de arroz em casca apontam características não lineares, uma vez que o teste LR rejeita a hipótese nula de linearidade. Desta forma, a especificação com mudança de regime selecionada de acordo com os critérios de comparação segue um MSI(3)VEC(1), sendo que os três regimes são classificados como anteriormente.

$$
\begin{aligned}
& \Delta q_{c_{t}}=\underset{(0,138)}{0,989 v_{1}}-\underset{(0,193)}{9,989 v_{2}}+\underset{(0,073)}{0,609 v_{3}-} \\
& -\underset{(0,073)}{095} \varepsilon_{c_{t-1}}-0 \underset{(0,108)}{812 \Delta q_{c_{t-1}}}-0 \underset{(0,686)}{130 \Delta i n d_{b_{t-1}}}+ \\
& +\underset{(2,906)}{5} \underset{t}{54} y_{t-1}-1, \underset{(0,354)}{298 \Delta p m} 3_{c_{t-1}}+\underset{(0,457)}{0,268 \Delta p d 2_{c_{t-1}}}
\end{aligned}
$$

Os parâmetros relacionados ao preço doméstico e à produção industrial não foram significativos. Já o ajuste de curto prazo para o arroz em casca, representado na equação 11 , comparativamente ao mensal, subiu para cerca de $70 \%$. O parâmetro exibido pela renda demonstra que elevações da renda no trimestre anterior são revertidas em um consistente aumento das importações no período seguinte. Já a elasticidade-preço de importação tem resultados que contrastam com sua versão linear. Nesse caso, a estimativa não linear demonstra que os importadores ajustam a quantidade no período dada uma elevação do preço do bem substituto no trimestre anterior.
O ajuste para o preço doméstico, mesmo que pequeno e não significativo, acontece no modelo com mudança de regime, enquanto que para o modelo linear a resposta à elevação de preço levou dois trimestres.

As estimativas das probabilidades de transição entre os três estados indicam resultados próximos do modelo mensal. Segundo a matriz de probabilidade de transição em 12, a probabilidade de se estar em um regime de queda das importações e assim permanecer, dado por $p_{11}=0,81$, é menor do que a probabilidade de se estar em um regime de expansão da demanda e nele permanecer, $p_{33}=0,87$. Entretanto, a probabilidade de se estar em um regime de estabilidade das importações e nele permanecer, dado por $p_{22}=0,92$, é maior que os demais.

$$
P_{c}=\left[\begin{array}{lll}
0,810 & 0,000 & 0,073 \\
0,190 & 0,920 & 0,057 \\
0,000 & 0,080 & 0,870
\end{array}\right]
$$

O período mais longo das expansões (regime 3) chega a 15 trimestres consecutivos, ao passo que quedas na demanda (regime 1) chagaram a oito trimestres consecutivos. Nesse caso, destaca-se a retração ocorrida entre o primeiro trimestre de 2004 e o quarto de 2005. Já períodos mais estáveis (regime 2), além de mais frequentes, são, em média, as mais longas (12,49 trimestres), contra 5,25 e 7,74 trimestres dos regimes 1 e 3, respectivamente.

Para o modelo linear trimestral de arroz beneficiado da equação 13, os resultados sugerem um comportamento semelhante ao modelo mensal ${ }^{16}$. A elasticidade-renda, além de elástica, expôs as características de bem inferior, enquanto a produção industrial de arroz ressaltou que períodos de elevada produção interna inibem a importação de arroz beneficiado. $\mathrm{O}$ coeficiente relacionado ao preço doméstico mostrou-se inferior à unidade. Entretanto, a elasticidade-preço de importação evidenciou sinal contrário ao esperado.

\footnotetext{
16. O modelo linear de longo prazo foi definido por $q_{b_{i}}=\underset{(1,467)}{8,094-}$ $-\underset{(0,28)}{0,820 i n d} d_{b_{i}}-\underset{(0,316)}{1,609 y_{t}}+\underset{(0,086)}{0,790 p d 1_{b_{t}}}+\underset{(0,748)}{0,748 p m} 4_{c_{i}}+\underset{(0,180)}{0,180 q_{b_{t-1}}}+\varepsilon_{t}$.
} 
Chama-se a atenção para a ausência de cotação externa do produto beneficiado (esse parâmetro tinha como fonte o preço pago ao arroz em casca ao produtor americano).

$$
\begin{aligned}
& \Delta q_{b_{t}}=\underset{(0,048)}{0,038}-\underset{(0,119)}{0,225} \varepsilon_{b_{t-1}}-\underset{(0,127)}{0,266 \Delta q_{b_{t-1}}}+
\end{aligned}
$$

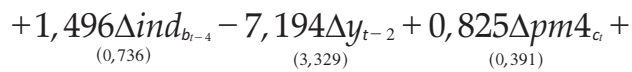

$$
\begin{aligned}
& +0,887 \Delta p d 1_{b_{t}} \\
& (0,438)
\end{aligned}
$$

Lembrando que os testes de raiz unitária indicaram que as variáveis em questão são I(1), os resultados dos testes de cointegração evidenciaram a existência de pelo menos um vetor de cointegração, ao passo que, para o teste de Gregory e Hansen (1996), assim como na versão mensal, não foi possível rejeitar a hipótese nula em todos os modelos testados ${ }^{17}$. Os resultados sugerem um ajuste de curto prazo mais lento em relação ao modelo de arroz beneficiado mensal. Ressalta-se também que o ajuste das importações a variações positivas nos preços internos e internacionais não são compensados no período.

O teste LR revelou a não linearidade do sistema $\chi_{(4)}^{2}=24,672$, justificando a necessidade de se estimar um modelo com mudança de regime. No caso do arroz beneficiado, selecionou-se um modelo com três estados igualmente ao modelo mensal, com mudança de regime no intercepto e variância, MSIH(3)-VEC(1) representado por (4.11). Comparando os resultados, o ajuste de curto prazo do modelo trimestral é mais lento (22\%) frente ao mensal. Embora os parâmetros relacionados com expansões (regime 3) e a indústria de beneficiamento não sejam significativos, sua estabilidade foi superior ao modelo mensal para o arroz beneficiado. Conforme os resultados encontrados, ajustes a variações positivas no preço internacional no trimestre anterior são compensados no período, ao passo que esse resultado contrasta com o modelo não linear mensal e linear trimestral. Já elevações do preço doméstico

17. Optou-se pela estimação do vetor, dado por $\theta=[1 ;-5,408$; $-1,873 ; 1,036 ; 1,382 ; 26,945 c]$, para a construção de um modelo de correções de erros. tendem a influenciar menos que proporcionalmente as importações no período seguinte.

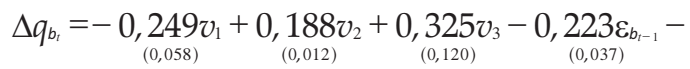

$$
\begin{aligned}
& -0, \underset{(0,031)}{327 \Delta i n d_{b_{t-1}}}+\underset{(0,195)}{080} \underset{i n d_{b_{t-1}}}{0}+\underset{(0,817)}{1,434 \Delta y_{t-1}-} \\
& -1, \underset{(0,172)}{201 \Delta p m} 4_{c_{t-1}}+\underset{(0,148)}{0,731 \Delta p d 1_{b_{t-}}}
\end{aligned}
$$

Pela matriz de transição mostrada em 15, a probabilidade de se estar em um regime de queda das importações e assim permanecer, dado por $p_{11}=0,66$, é menor do que a probabilidade de se estar em um regime de expansão da demanda e nele permanecer, $p_{33}=0,74$. No entanto, a probabilidade de se estar em um regime de estabilidade das importações e nele permanecer, dado por $p_{22}=0,52$, é menor que os demais. O regime 3, com duração de 3,86 trimestres, é o mais longo deles, contra 2,95 trimestres do regime 2. Períodos de expansão da demanda (regime 3) são os mais longos, mas menos frequentes que o regime 2 . Já as contrações da demanda (regime 1), embora frequentes, não ultrapassaram seis trimestres consecutivos.

$$
P_{b}=\left[\begin{array}{lll}
0,660 & 0,464 & 0,013 \\
0,219 & 0,528 & 0,245 \\
0,121 & 0,008 & 0,742
\end{array}\right]
$$

Para o período de ausência de restrição tarifária, entre junho de 2001 e dezembro de 2002, o modelo com dados trimestrais possibilita melhor observação de que são os regimes de expansão que governam as importações em quatro dos seis trimestres identificados. Já o incentivo tarifário concedido pelo governo brasileiro para fomentar as importações, entre outubro e dezembro de 2003, está dentro do período de vigor do regime 2.

Pelas estimativas trimestrais, depreende-se que atribuir a elevação da renda após a estabilização conseguida com o Plano Real como um catalisador das importações de ambos os tipos, seja casca ou beneficiado, somente é possível quando a variável utilizada é o salário médio da indústria e não o PIB. Vale lembrar, conforme Coelho et al. (2009), que uma parcela do aumento da renda no Brasil tem sido revertido em consumo 
do cereal. Mas a introdução dos regimes também deixa a percepção que parte desse aumento tem sido suprida pela elevação da produção nacional e não pela importação de cereal. A opção do modelo de mudança de regime para o arroz em casca e beneficiado trimestral mostra que os desequilíbrios mantiveram as magnitudes de ajustes próximas das estimativas lineares. Revela também que, embora os regimes de expansão das importações sejam significativos em ambos os casos, sua duração para o beneficiado foi mais longa quando comparado a períodos de queda, mas menos frequente. As matrizes de transição também ressaltam o caráter dominante dos regimes de estabilidade e suas características: em um primeiro momento, foram rompidos na integração do Mercosul e, depois, esse regime volta a se repetir sob o risco desabastecimento por problemas climáticos e via estímulo tarifário (redução da tarifa). Esse novo argumento não enfraquece a importância que a literatura tem dado para as flutuações do câmbio, mas apenas reforça a necessidade de se estudar os regimes de uma variável dentro de diferentes periodicidades.

\section{Conclusões}

O objetivo principal desse trabalho foi avaliar os determinantes da importação brasileira de arroz pós-união aduaneira do Mercosul. O período compreende importantes eventos que influenciaram a economia e as relações comerciais no Cone Sul. A investigação seguiu a proposta na literatura da área ao usar um modelo que pudesse representar as elasticidades de curto e longo prazo. Nesse caso, a maior contribuição está na adaptação de modelos não lineares, como os que incorporam mudanças de regime markoviano ao comportamento da demanda por importação de arroz. Essa contribuição foi significativa, na medida em que os resultados contrastaram com modelos utilizados anteriormente. $\mathrm{O}$ modelo com mudança de regime também ressaltou comportamentos distintos para os parâmetros mediante a mudança de variáveis explicativas, periodicidade e entre os tipos de arroz, quando considerados separadamente.

De forma geral, na periodicidade mensal, nota-se a maior contribuição da renda para o aumento da importação de arroz em casca, embora o mesmo não possa ser afirmado para o arroz beneficiado. Com a mudança na periodicidade dos dados, os resultados trimestrais diferiram substancialmente, na medida em que predominou um comportamento de bem inferior para ambos os tipos de arroz. Esse comportamento foi discutido e verificado em estudos anteriores, que ressaltaram as mudanças dos hábitos alimentares do brasileiro ao longo dos anos. De todo modo, não é possível afirmar que a melhora da renda, quando medida pela variável PIB, seja a principal causa da elevação da demanda por arroz. Porém, quando se usa o salário da indústria como proxy da renda, os resultados são diferentes.

A magnitude das elasticidades estimadas para o preço doméstico foram superiores à unidade apenas nos modelos para o arroz em casca. Isso reforça que o custo financeiro com a aquisição do cereal no mercado interno tem impacto significativo nas importações de arroz em casca. Já para o arroz beneficiado, as elasticidades permaneceram inferiores à unidade, embora os sinais tenham seguido o modelo econômico proposto, ou seja, alterações de preço interno não apresentam impacto significativo para as importações.

Quanto ao bem substituto externo, a elasticidade-preço mostrou-se perfeitamente condizente com a teoria. Contudo, o preço internacional de arroz não pode ser apontado como o principal catalisador das importações de arroz em casca no período. A falta de expressividade também se verificou para o arroz beneficiado, porém, com sinal inverso, e isso levanta indícios de que a cotação externa e o câmbio perderam influência sobre as importações. Essa afirmação é reforçada pelo grau de defasagem dos agentes frente a alterações do mercado, pois aumentos de preço no mês anterior não são compensados no período, na totalidade dos casos. Acredita-se, então, que esse comportamento possa ser explicado em 
função dos contratos de importação já tratados, o que pode limitar a tomada de decisão do agente.

No caso da atividade industrial, observa-se uma relação pró-cíclica entre a indústria de beneficiamento e as importações mensais de arroz em casca, enquanto há uma relação inversa quando se observa o lado da demanda pelo arroz beneficiado. Sendo assim, do ponto de vista do produtor de arroz é desejável maior articulação entre governo e indústria que vise compensar a queda do preço ao produtor durante o período de colheita. Já para os modelos trimestrais, o resultado não se repetiu, tendo predominado o comportamento contracíclico com a demanda, sinalizando uma absorção interna, ou via estoques, em detrimento das importações.

As correções dos desequilíbrios foram mais elevadas para o modelo mensal de arroz beneficiado, assim como para o arroz em casca trimestral. A introdução da formulação MS com três regimes de importações para ambos os casos levou a uma atenuação da velocidade da correção dos desequilíbrios de curto prazo com dados mensais, enquanto manteve-se estável nas estimativas trimestrais.

Nesse caso, algumas conclusões são reforçadas, tais como: a importância da política comercial para a demanda por importação de arroz e a significativa influência dos fenômenos climáticos adversos sobre os regimes de expansão das importações. Para o arroz em casca, a estabilidade da demanda tende a ser mais longa nas estimativas trimestrais. Isso chama a atenção para a influência do governo sobre os volumes importados via incentivo tarifário com terceiros - o que se mostra útil para contornar períodos de escassez de oferta no Brasil e no Mercosul - e manutenção de estoques reguladores. Esse comportamento demonstra que todo o esforço voltado para a expansão da produção interna, via incrementos de produtividade, é válido para manter a competitividade do setor. Em destaque, o risco de se criar um mercado de arroz isolado via imposição de tarifas de importação proibitivas no bloco, leia-se desvio de comércio.

Como sugestão de trabalho futuro que podem contribuir com as evidências aqui apontadas está a construção de indicadores coincidentes e antecedentes das importações, além do uso de equações simultâneas.

\section{Referências bibliográficas}

BRAGA, H. C. e MARKWALD, R. A. Funções de oferta e de demanda das exportações de manufaturados no Brasil: estimação de um modelo simultâneo. Brasília: IPEA, 1983. (Texto para Discussão Interna n. 57).

BRY, G. e BOSCHAN, C. Cyclical Analysis of Time Series: Selected Procedures and Computer Programs, NBER Technical Paper 20, 1971.

CAPITANI, D. H. D., MIRANDA, S. H. G. de e FERNANDES, E. A. Determinantes da demanda por importação de arroz do Mercosul. Revista de Economia e Sociologia Rural, Brasília, v. 49 n. 3, jul./set., 2011.

CARVAlHO, A. e PARENTE, M. A. Estimação de Equações de Demanda de Importações por categoria de Uso para o Brasil (1978/1996). Brasília: IPEA, abr. 1999. (Texto para discussão, 636).

CARVALHO, A. e NEGRI, J. A. Estimação de Equações de Importação e Exportação de Produtos Agropecuários para o Brasil (1977/1998). Brasília: IPEA, jan. 2000. (Texto para discussão, 698).

CASTRO, A. S. e CAVALCANTI, M. A. F. H. Estimação de equações de exportação e importação para o Brasil 1955/1995. Rio de Janeiro: IPEA, mar. 1997 (Texto para Discussão, 469).

COELHO, A. B., AGUIAR, D. R. D. e FERNANDES, E. A.. Padrão de consumo de alimentos no Brasil. Revista de Economia e Sociologia Rural, Brasília: v. 47 n. 2, abr./ jun., 2009.

DIB, M. de F. S. P. Equações para a demanda de importações, Brasil: 1960-1979. Revista Brasileira de Economia, Rio de Janeiro, v. 35, n. 4, out./dez. 1981.

FAO - Food and Agriculture Organization. Rice Market Monitor. Volume XII - Issue No. 4. Dec 2011.

FRANKEL, J. A. e ROSE, A. K. Determinants of Agricultural and Mineral Commodity Prices. In: Preconference Westfälische Wilhelms University Münster, Muenster, Germany. Anais eletrônicos... Germany: Muenster, jun. 2009.

GOLDSTEIN, M. e KHAN, M. S. The supply and demand for exports: a simultaneous approach. The Review of Economics and Statistics, v. 60, n. 2, p. 257-286, 1978. 
GOOD D. e IRWIN S. Implications of Credit Market Problems for Crop Prices. In: Illinois Farm Economics Update, Department of Agricultural and Consumer Economics, University of Illinois at UrbanaChampaign, 2008. Disponível em: <http://www. farmdoc.uiuc.edu/IFEU/IFEU_08_03/IFEU_08_03. pdf> . Acesso em: 2 abr. 2010.

GREGORY, A. W. e HANSEN, B. E. Residual-based tests for cointegration in models with regime shifts. Journal of Econometrics, v. 70, n. 1, p. 99-126, 1996.

HAMILTON, J. D. A New Approach to the Economic Analysis of Nonstationary Time Series and the Business Cycle, Econometrica, v. 57, p. 357-384, 1989.

IRWIN, S. H., SANDER, D. R. e MERRIN, R. P. Devil or Angel? The Role of Speculation in the Recent Commodity Price Boom (and Bust). Journal of Agricultural and Applied Economics, v. 41, n. 02, ago. 2009.

JOHANSEN, S. Statistical analysis of cointegration vectors. Journal of Economic Dynamics and Control, n. 12, p. 231-254, 1988.

KROLZIG, H.-M. Statistical analysis of cointegrated VAR Processes with Markovian Regime Shifts. SFB 373, Berlin, Humboldt Universitat, 1996. (Discussion Paper, n. 25).

KROLZIG, H.-M. Econometric modeling of Markovswitching vector autoregressions using MSVAR for $O x$, Department of Economics, University of Oxford, 1998. (Discussion Paper).

LEAMER, E. E. e STERN, R. M. Quantitative international economics. Allyn and Bacon, 1970. 209 p.

MDIC - Ministério do Desenvolvimento, Indústria e Comércio. Disponível em: <http://www. desenvolvimento.gov.br/sitio/inicial/index.php $>$. Acesso em: 29 mar. 2011.

MORAIS, I. A. C. e PORTUGAL, M. S. A markov switching model for the Brazilian Demand for Imports: Analyzing the import substitution process in Brazil. Revista de Econometria, Rio de Janeiro, v. 25, n. 2, p. 173-219, 2005.

MORAIS, I. A. C., BERTOLDI, A. e ANJOS, A. T. M. Estimativa de um modelo não-linear para as exportações brasileiras de borracha no período 19922006. Revista de Economia e Sociologia Rural, Brasília, v. 48, n. 3, jul./set. 2010.
NG, S. e PERRON, P. Lag Length Selection and the Construction of Unit Root Tests with Good Size and Power". Econometrica, v. 69, p. 1519-1554, 2001.

NONNENBERG, M. J. B. e MENDONÇA, M. J. C. Criação e Desvio de Comércio no rcosul: o caso dos produtos agrícolas. Rio de Janeiro: IPEA, Mar. 1999. (Text for discussion, 631).

OSAKI, M. Determinantes da oferta e da demanda por cebola argentina no Brasil nos anos 90. 2003. 101f. Dissertação (Mestrado em Economia Aplicada) - Escola Superior de Agricultura Luiz de Queiroz, Universidade de São Paulo, São Paulo.

PERRON, P. The Great Crash, the Oil Price Shock, and the Unit Roots Hypothesis. Econometrica, v. 57, p. 13611401, 1989.

PERRON, P. Further evidence on breaking trend functions in macroeconomic variables. Journal of Econometrics, n. 80, p. 355-385, 1997.

PEROTTI, A. D. El arroz... la gran base... para uma decisión que afianza el Derecho Mercosur (Medidas Cautelares): La sentencia del Superior Tribunal de Justiça del 8 de junio de 2000. Revista de Direito do Mercosul, ano 4, n. 4, ago. 2000, p. 237-244.

PORTUGAL, M. S. Um modelo de correção de erros para a demanda por importações brasileira. Pesquisa e Planejamento Econômico, Rio de Janeiro, v. 22, n. 3, dez. 1992. p. 501-540.

PORTUGAL, M. S. Equilibrium models of trade equations: A critical review. Análise Econômica, Porto Alegre, Ano 11, p. 69-91, 1993.

RESENDE, M.F.C.Crescimento Econômico, Disponibilidade de Divisas e Importações Totais e por Categoria de Uso no Brasil: Um Modelo de Correção de Erros. Brasília: IPEA, mar. 2000. (Texto para discussão, 714).

SANTOS, D. F. e BARROS, G. S. C. Importações brasileiras de leite: impactos micro e macroeconômicos. Economia Aplicada, v. 10, n. 4, Ribeirão Preto, out/dez, p.541-549, 2006.

ZINI, A. A. Jr.. Funções de exportação e de importação para o Brasil. Pesquisa e Planejamento Econômico, v. 18, n. 3, 1988, p. 615-662. 
Tabela 1A. Critérios de informação para os modelos MS-VEC

\begin{tabular}{|c|c|c|c|c|c|c|c|c|c|c|c|c|}
\hline \multirow{3}{*}{ Modelo } & \multicolumn{12}{|c|}{ Formas funcionais modelos mensais VEC(1) } \\
\hline & \multicolumn{3}{|c|}{ Casca } & \multicolumn{3}{|c|}{ Beneficiado } & \multicolumn{3}{|c|}{ Casca } & \multicolumn{3}{|c|}{ Beneficiado } \\
\hline & $A I C^{*}$ & $H Q$ & SIC & AIC & $H Q$ & SIC & AIC & $H Q$ & SIC & AIC & $H Q$ & SIC \\
\hline $\mathrm{MSH}(2)$ & 1,559 & 1,637 & 1,751 & 0,958 & 1,035 & 1,150 & 1,791 & 1,941 & 2,175 & 1,054 & 1,204 & 1,438 \\
\hline $\operatorname{MSI}(2)$ & 1,680 & 1,758 & 1,872 & 1,037 & 1,115 & 1,229 & 1,681 & 1,831 & 2,065 & 0,979 & 1,130 & 1,363 \\
\hline MSIA(2) & 1,654 & 1,774 & 1,951 & 1,011 & 1,132 & 1,308 & 1,729 & 1,961 & 2,322 & 0,879 & 1,111 & 1,473 \\
\hline MSIAH(2) & 1,563 & 1,690 & 1,877 & 0,945 & 1,073 & 1,260 & 1,613 & 1,859 & 2,241 & 0,820 & 1,066 & 1,449 \\
\hline MSIH(2) & 1,566 & 1,651 & 1,776 & 0,926 & 1,011 & 1,136 & 1,705 & 1,868 & 2,123 & 1,002 & 1,166 & 1,421 \\
\hline $\operatorname{MSM}(2)$ & 1,680 & 1,758 & 1,872 & 1,037 & 1,115 & 1,229 & 1,685 & 1,835 & 2,069 & 0,963 & 1,113 & 1,347 \\
\hline MSMH(2) & 1,569 & 1,654 & 1,779 & 0,927 & 1,012 & 1,137 & 1,753 & 1,917 & 2,172 & 0,980 & 1,144 & 1,399 \\
\hline $\mathrm{MSH}(3)$ & 1,612 & 1,726 & 1,892 & 0,980 & 1,094 & 1,260 & 1,959 & 2,177 & 2,517 & 1,220 & 1,439 & 1,779 \\
\hline MSI(3) & 1,561 & 1,674 & 1,840 & 0,975 & 1,088 & 1,254 & 1,390 & 1,608 & 1,948 & 1,119 & 1,337 & 1,677 \\
\hline MSIA(3) & 1,603 & 1,801 & 2,092 & 0,919 & 1,117 & 1,408 & 1,363 & 1,745 & 2,341 & 0,780 & 1,162 & 1,757 \\
\hline MSIAH(3) & 1,529 & 1,741 & 2,053 & 0,891 & 1,103 & 1,415 & 1,318 & 1,727 & 2,365 & 0,551 & 0,961 & 1,599 \\
\hline MSIH(3) & 1,571 & 1,698 & 1,885 & 0,979 & 1,106 & 1,293 & 1,442 & 1,688 & 2,071 & 0,876 & 1,122 & 1,504 \\
\hline $\operatorname{MSM}(3)$ & 1,735 & 1,848 & 2,014 & 0,97 & 1,086 & 1,252 & 1,522 & 1,740 & 2,080 & 1,084 & 1,302 & 1,643 \\
\hline MSMH(3) & 1,494 & 1,621 & 1,808 & 0,991 & 1,118 & 1,305 & 1,552 & 1,79 & 2,180 & 0,961 & 1,206 & 1,589 \\
\hline Linear & 1,648 & 1,704 & 1,787 & 1,004 & 1,061 & 1,144 & 1,702 & 1,811 & 1,981 & 0,954 & 1,063 & 1,233 \\
\hline
\end{tabular}

* Tal que AIC corresponde a Akaike information criterion; SIC para Schwarz information criterion; e HQ para Hannan-Quinn criterion.

Fonte: Elaborado pelos autores. 